ISSN: 1641-4713; e-ISSN: 2081-1160

DOI: https://doi.org/10.36551/2081-1160.2021.28.75-94

\title{
A Revolução dos generais: (Des)encontros entre movimentos sociais e o governo militar boliviano após o golpe de 1964
}

\author{
The Generals' Revolution: (Mis)encounters between social movements \\ and the Bolivian military government after the 1964 coup
}

\author{
Guilherme de Moraes Andrade \\ Pontifícia Universidade Católica do Rio de Janeiro, Brasil \\ ORCID iD: https://orcid.org/0000-0002-6317-0723 \\ E-mail: guilherme.mandrade@gmail.com
}

Recepción: 31.05.2021

Aprobación: 6.12.2021

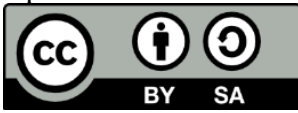

Resumo: Este trabalho tem por objeto investigar as relações entre o governo militar que se estabelece na Bolívia após 1964 e os movimentos sociais, em especial, de trabalhadores das regiões mineiras e agrárias. A forma como os movimentos trabalhistas no setor de mineração foram perseguidos contrasta fortemente com o apoio demonstrado pelas organizações camponesas, sustentado pela promessa de redistribuição de terras no campo. Todavia, a correlação traçada pelos militares entre a efetivação da reforma agrária e o combate ao radicalismo popular resulta de uma inflexão com o arranjo original da reforma, produto do governo da Revolução Nacional de 1952. A maneira como os movimentos sociais, protagonistas do episódio, haviam passado a fazer parte dos cálculos políticos resultaria em um complexo e contínuo processo de negociação das identidades sociais vis-àvis umas às outras. Enxergar esse objeto histórico a partir dessa chave relacional, em detrimento de uma redução do conflito social à conjuntura da Guerra Fria, permite abordar a articulação que os atores sociais fazem a respeito dos termos em que podem ser vistos e ouvidos no debate público.

Palavras-chave: América Latina, movimentos sociais, sindicalismo, Bolívia, Guerra Fria

Abstract: The article aims to investigate the relationship between the Bolivian military government, established after a coup in 1964, and social movement, in special unionized workers in mining and rural areas. The way labor movements in the mining sector have been persecuted contrasts heavily with the support shown by peasant organizations, held by the promise of land redistribution 
in the rural area. However, the way the military have associated the fulfillment of the agrarian reform to the repression of popular radicalism poses a different perspective from those upheld by the originators of the reform, the government of the 1952 National Revolution. The manner social movements, due to the major role they played in the episode, came to be included in political calculation had resulted in a complex, and continuous, process of negotiation among social identities. Approaching this process as a historical object through a relational outlook, instead of reducing it to the Cold War conjunctural framework, allows us to address the articulations drawn by social actors, regarding the terms on how they may be seen or heard inside the public debate.

Keywords: Latin America, social movements, labor unions, Bolivia, Cold War

\section{INTRODUÇÃO}

Em um país marcado por uma forte tradição sindical, a busca pela legitimidade popular havia se tornado incontornável para os dirigentes políticos bolivianos desde a Revolução Nacional de 1952, quando a derrubada da antiga oligarquia pós-independência colocara em pauta reformas econômicas, políticas e sociais que anunciavam garantir o desenvolvimento nacional a todos os bolivianos. Entretanto, apesar dessa aparência cumulativa e unidirecional do processo histórico, os significantes da tradição e do progresso, da ordem e da mudança, iriam articular-se de modos pouco lineares (Rivera, 2012). Após a derrubada do governo revolucionário por um golpe militar em 1964, que levou a um racha nos movimentos sociais, e enquanto sindicatos camponeses declaram seu apoio aos generais, trabalhadores urbanos e das minas seriam vítimas de uma dura repressão autoritária. Nesse sentido, abordar esse período de consolidação da Bolívia moderna demanda um olhar atento à forma pela qual os grupos que a compõem são capazes de se fazer presentes, não apenas reproduzindo na prática categorias analíticas universais, mas assumindo distintas facetas para que suas demandas sejam compreendidas no debate público.

O trabalho propõe abordar o desenvolvimento dos conflitos sociais bolivianos durante as décadas de 1960 e 1970, baseado na proposta de Rivera (2010), de dois horizontes históricos distintos para entender os movimentos camponeses nesse período: um mais 'contemporâneo', em diálogo com as lutas populares de trabalhadores nas cidades e nas minas, e outro mais 'tradicional', ligado ao histórico de resistência no interior do processo colonial. Aqui, esse movimento de sobreposição entre narrativas trata a problemática a partir do deslocamento de seus sentidos históricos, através de uma revisão bibliográfica contrapondo distintos enquadramentos da intrincada tapeçaria social que forma o país e os conflitos que o atravessam. Estes sentidos organizam tanto a narrativa que as relações sociais produzem sobre si mesmas, quanto a maneira como somos capazes de recuperá-las. Portanto, 
mobilizá-los enquanto objeto de investigação nos leva a olhar para as diferentes formas de transmitir um determinado sentido a respeito do passado (White, 1980).

Este trabalho não se propõe a esgotar a discussão bibliográfica existente sobre os movimentos sociais bolivianos, nem a relação deles com o Estado durante os conflitos vigentes ao longo do período militar. O objetivo é investigar, como propõe Shapiro (2013), o efeito alcançado ao contrapormos um determinado questionamento histórico (por que os movimentos camponeses em um primeiro momento se alinham aos militares, em oposição os sindicatos?) com as condições de possibilidade para que ele possa ser efetivado. O resultado é uma tentativa de desvincular as posições sociais de um circuito inequívoco de identificações: a linha que separa o camponês e o indígena começa a se borrar, assim como aquela que divide a busca pelo progresso, o regate do que se foi e a conservação do que parece sob risco de perder-se.

Desse modo, a primeira sessão irá abordar o alinhamento entre os movimentos camponeses e os militares, a partir do vínculo estabelecido entre o aprofundamento da redistribuição de terras no espaço agrário e o combate aos setores mais radicalizados do sindicalismo rural, mineiro e urbano. Na segunda parte, são investigados os sentidos que orbitam o sindicato rural, sua relação com a racialidade na Bolívia pós-revolucionária e sua complexa articulação entre modos modernos e locais de organização política que influi na possibilidade de que populações historicamente negligenciadas no debate público pudessem assumir uma voz compreensível pelas demais forças políticas. Isso nos permite apreender o caráter histórico e relacional dessas identidades e adquirir um outro olhar para o progressivo esgotamento do governo militar, em especial no reencontro entre os distintos movimentos de trabalhadores. Na última sessão, discute-se a emergência no interior do sindicalismo camponês do movimento katarista, cuja ênfase no resgate da identidade indígena caminha ao lado de novas possibilidades articulatórias para os distintos movimentos sociais do campo, das cidades e das minas. Observar esse processo de desenvolvimento do corpo social e das posições que o compõem, decompostas em suas articulações históricas conjunturais, nos permite um olhar mais aprofundado para o período autoritário vivido pela América Latina a partir dos movimentos populares.

\section{RADICALISMO, REFORMA, REVOLUÇÃO}

Assim como seus vizinhos do Cone Sul, a Bolívia atravessou durante a segunda metade do século XX um período autoritário marcado pela oposição entre as forças armadas e setores dissidentes da sociedade civil. Duramente 
perseguidos, importantes movimentos sociais como os sindicatos da indústria mineradora, o mais relevante setor econômico do país à época, foram obrigados a agir durante anos na clandestinidade, com diversas lideranças sendo exiladas, presas, mortas ou difamadas publicamente. Na Bolívia militar das décadas de 1960 e 1970, auge da Guerra Fria, o objetivo central era a eliminação do radicalismo, em um alinhamento claro com a doutrina estadunidense de segurança. A morte de Ernesto Che Guevara por forças especiais treinadas pelos norte-americanos, em outubro de 1967, lançou o general René Barrientos, primeiro presidente desse período militar, nas graças dos líderes ocidentais (Alexander, 2005). Esse rápido episódio, onde a Bolívia se revela como um dos palcos da intensa luta ideológica travada a nível global, aponta aparentemente para uma primeira interpretação acerca das razões por trás do período autoritário vivido pelo país. Todavia, suas ramificações na política nacional traçam uma rede mais complexa de sentidos, identificações, interesses, alianças e antagonismos entre militares e movimentos sociais, contrapondo-se à redução do local a um mero epifenômeno de processos políticos a nível global.

As forças armadas haviam tomado o poder através de um golpe de estado em novembro de 1964, entrando quase imediatamente em conflito com grande parte dos movimentos de trabalhadores. Após o sucesso da Revolução Cubana (e de uma passagem pela África), Guevara se dirigiu, em 1966, à Bolívia, com a intenção de mobilizar uma guerrilha contra o governo. Como narra Guillermo Lora (1977), seu grupo foi alvo de declarações de apoio por parte de lideranças sindicais em Catavi, que em uma assembleia, poucos meses antes da sua morte, aprovaram uma moção para enviar-lhe comida e medicamentos. Em um período de recrudescimento da relação do governo com os sindicatos, foi agendado nesse mesmo encontro um grande protesto em Potosí, no centro minerador de CataviSiglo XX, um dos maiores do país. Na véspera da mobilização, marcada para 24 de junho, os trabalhadores e suas famílias se reuniram para celebrar a noite de San Juan, uma importante festa popular no interior da Bolívia. Mas horas antes do amanhecer, em meio às fogueiras acesas na plaza del Minero, começaram a surgir soldados pertencentes à mesma unidade treinada para combater a guerrilha de Guevara. No final, o saldo foi de vinte mortos e mais de setenta feridos. $\mathrm{O}$ enterro foi acompanhado por trinta mil pessoas, que protestaram contra o ataque do governo aos trabalhadores desavisados.

A principal pauta dos protestos era o retorno dos salários da estatal Corporación Minera de Bolivia (COMIBOL) aos níveis anteriores a 1965, quando o recém-empossado Barrientos anunciara importantes mudanças na administração da empresa (Alexander, 2005). O uso, na repressão aos trabalhadores, das 
mêsmas forças treinadas para capturar Guevara e a preocupação de que a pauta econômica dos protestos escondesse intenções subversivas remetem à típica associação entre os regimes militares latino-americanos do século XX e a garantia da ordem e da estabilidade nacional contra a "ameaça comunista", projetada sobre distintos movimentos sociais e populares críticos ao governo. A abertura da COMIBOL ao capital estrangeiro, que ensejara cortes nos salários e a redução da influência dos sindicatos em sua administração, seria marcante das reformas econômicas introduzidas pelo regime autoritário, em linha com essa tentativa de minar as bases para uma revolta popular (ibid.). Entretanto, apesar do novo governo diferir em muitos pontos de seus antecessores, o golpe de 1964 não era entendido pelos militares como o início do processo de transformação do país, mas como seu aprofundamento, sendo para isso necessário o combate a toda forma de radicalismo que pusesse as reformas em risco. (Rivera, 2010).

A defesa da ordem era associada à consolidação de nova Bolívia nascida após os episódios da Revolução Nacional, ocorrida doze anos antes. O evento de 1952 havia sido marcado pela derrubada da oligarquia que ocupava o Estado desde a independência em 1825, conhecida por la rosca. Por meio de uma aliança sem precedentes entre setores populares e de classe média, a revolução resultou na nacionalização da indústria mineradora e na criação da COMIBOL, e deu início a uma profunda reforma agrária, cuja promessa de continuação seria a principal fonte de apoio popular ao governo Barrientos. Foi também nesse período que surgiu a Central Obrera Boliviana (COB), principal órgão sindical do país a nível nacional, resultado direto da participação dos trabalhadores mineiros na derrubada da antiga oligarquia. Os doze anos posteriores a 1952 veriam a hegemonia do Movimiento Nacionalista Revolucionário (MNR), formado por setores de classe média e com alianças que se estendiam igualmente às lideranças sindicais e às altas patentes do exército. O governo movimientista buscou marcar desde o princípio suas diferenças em relação à elite latifundiária e os grandes empresários da mineração, afirmando seu objetivo de garantir que as riquezas do país contribuíssem para o desenvolvimento de uma nação inclusiva e próspera. (Webber, 2011).

O período do MNR à frente do país encontraria seu fim nas mãos do então vice-presidente Barrientos, que gozava de grande apoio dos dirigentes rurais. Barrientos ganhara popularidade entre o campesinato após ser destacado para lidar com conflitos entre lideranças locais em Cochabamba, recebendo o título de 'pacificador do Vale' (Soto, 1994). A região, onde haviam surgido na década de 1930 os primeiros sindicatos rurais, era o principal bastião de apoio à reforma agrária. Comparado com as montanhosas regiões de La Paz, Oruro e Potosí, em Cochabamba havia uma menor presença das comunidades indígenas conhecidas 
por ayllus, caracterizadas pelo uso coletivo da terra (Rivera, 2010). O solo fértil da região havia sido historicamente ocupado por pequenos proprietários, que através de um intercâmbio com setores da militância urbana desenvolveram o modelo sindical de organização, um dos grandes responsáveis pela forte presença popular na política boliviana do século XX, simultaneamente ao seu surgimento nas cidades (Pearse, 1972). No decreto de reforma agrária, de 1953, o sindicato rural cochabambino se tornaria o modelo oficial para operacionalizar a redistribuição das terras por todo o território do país. ${ }^{1}$ As lideranças locais foram inseridas na estrutura burocrática do governo do MNR, filiando-se às diversas tendências em disputa por determinar o rumo das reformas lançadas após 1952, e estabelecendo um inédito canal de comunicação com o governo (Rivera, 2010).

Em abril de 1964, meses antes da derrubada do MNR, tem início o chamado Pacto Militar-Campesino (PMC), onde as forças armadas se comprometiam a garantir a continuidade das reformas no espaço agrário em troca do apoio dos sindicatos rurais na repressão a 'radicalismos' que colocassem em risco a estabilidade do país, do governo e da revolução (Soto, 1994). A chegada do MNR ao poder contara com o apoio de milícias de trabalhadores, especialmente nas regiões mineradoras. Com a ajuda de um motim na polícia, elas haviam sido capazes de impingir, em 1952, uma derrota histórica aos militares, então principal setor de apoio à rosca (Alexander, 2005). Completamente desarticuladas, as forças armadas passariam por uma reestruturação com o apoio do Pentágono, a partir de 1956. A parceira era resultado de uma disputa interna no governo dos Estados Unidos a respeito da política diplomática para a América Latina. O enfoque no desarmamento dos setores populares, defendido pelos militares, concorria com a abordagem mais "branda" do Departamento de Estado, que apontava a democracia e o desenvolvimento econômico como os principais freios ao comunismo na região. À medida que as forças armadas recuperavam sua relevância no interior do Estado boliviano, os representantes sindicais perdiam espaço no gabinete presidencial do MNR (Lora, 1977).

O suporte do sindicalismo camponês, que havia pressionado os movimientistas a aceitarem Barrientos como vice na chapa presidencial de 1960,

\footnotetext{
${ }^{1}$ Em seu preâmbulo, o decreto de reforma agrária de 1953 apontava que a colonização espanhola havia violentamente deslocado o sistema "rudimentar" de gerenciamento da produção coletiva instaurado pelos Incas, em favor de uma economia extrativista e feudal. Essa elite latifundiária, baseada em técnicas pouco modernas e produtivas, era portanto a responsável pela exclusão do indígena da civilização. Desse modo, a marginalidade do indígena seria não de ordem racial, mas fundamentalmente uma questão econômica (Governo da Bolívia, 2018a). Esse perfil fica evidente na preferência pelo modelo parcelário cochabambino, em detrimento de experiências mais ligadas à manutenção cultural e social das comunidades indígenas no oeste do país.
} 
contrasta radicalmente com a forma como os demais movimentos de trabalhadores foram tratados nos anos que se seguiram ao golpe militar. Como ilustrado no Massacre da Noite de San Juan, o governo demonstrou pouca disposição em negociar com os mineiros. Estes tampouco gozavam do apoio de suas contrapartes rurais, uma vez que o PMC colocara a continuidade da reforma agrária em contraposição direta às aspirações socialistas de suas lideranças mais radicais (Soto, 1994). Em uma declaração emitida após o Massacre da Noite de San Juan, a federação departamental de camponeses de Cochabamba deixava claro sua visão a respeito dos sindicatos mineiros e dos acontecimentos em Catavi-Siglo XX:

As insurreições nos distritos mineradores são o fruto do trabalho de agitação e perturbação perpetrado por agentes do comunismo internacional. $\mathrm{O}$ que queremos reiterar para sua Excelência o Presidente da República, General don René Barrientos Ortuño, para seu governo constitucional e para as Forças Armadas da Nação, é nosso completo suporte moral e material nesse momento difícil, para que assim sua nobre tarefa de levar em frente o processo revolucionário possa continuar. (Alexander, 2005, p. 132) ${ }^{2}$

Após a morte de Barrientos, em um acidente de helicóptero em abril de 1969, haveria por um breve período no interior das forças armadas, acenos ao realinhamento com os demais sindicatos. O general Alfredo Ovando, principal rival do antigo presidente, tomaria o poder em setembro por meio de mais um golpe, anunciando rapidamente a nacionalização de grandes setores da indústria petroleira. ${ }^{3}$ Apesar da evidente tentativa de reavivar o sentimento nacionalista ligado à criação da COMIBOL, os trabalhadores já não mostravam a mesma disposição de 1952 a acreditar na convicção revolucionária dos demais grupos políticos (Lora, 1977). Ovando cairia para um novo golpe de Estado, em outubro de 1970, nas mãos do general direitista Rogelio Miranda. Um terceiro comandante, Juan José Torres, repudiou publicamente o ato e reivindicou para si a presidência, angariando o apoio da COB e dos movimentos estudantis na forma de uma greve geral. Torres havia sido afastado por Ovando por demonstrar 'exagerado apego à Revolução Nacional', e a mobilização que o garantiu na presidência reascendeu

\footnotetext{
${ }^{2}$ Todas as traduções para o português realizadas neste artigo foram feitas pelo autor.

${ }^{3}$ No discurso em que declarava a nacionalização das possessões da estadunidense Gulf Oil no país, Ovando (2018) traçaria um paralelo entre o tamanho e influência da empresa, por um lado, e o modo como a rosca dominara o Estado boliviano anteriormente à Revolução de 1952, por outro. Em sua defesa da soberania nacional, ele desenharia uma linha direta entre civilizações indígenas anteriores à conquista hispânica, os anos de luta pela independência da metrópole e o controle dos recursos naturais do país. Finalmente, ele faria também um paralelo entre a nacionalização do petróleo e a Guerra do Chaco, lutada entre 1932 e 1935 com o Paraguai pela posse das ricas jazidas da região (em uma época onde a estatal petrolífera boliviana ainda não havia sido criada), e cujo desfecho negativo para o exército boliviano deixaria a impressão de um conflito movido pelos interesses das elites, pouco preocupadas com o alto custo pago pelo povo.
} 
entre os trabalhadores as esperanças de que voltariam a intervir no governo. ${ }^{4}$ As tensões cresciam e ficava cada vez mais evidente entre as forças armadas que Torres não possuía qualquer controle sobre os sindicatos. Os rumores de um novo golpe voltaram a assombrar a capital La Paz, mas a despeito dos apelos dos trabalhadores, o presidente resistiu até o final em rearmar as milícias. O temor em perder o suporte das forças armadas, por um lado, e a falta de vigor revolucionário, por outro, deixariam Torres cada vez mais isolado. Em janeiro de 1971, o apoio dos movimentos sindicais foi essencial para debandar a primeira tentativa de golpe liderada pelo general Hugo Bánzer, mas este acabaria tendo sucesso poucos meses depois, em 20 de agosto, partindo de Santa Cruz e tomando La Paz em menos de um dia (Alexander, 2005; Lora, 1977).

Reconhecido pelas lideranças sindicais rurais como novo garantidor do PMC, Bánzer deixaria para trás a ênfase de Barrientos em desarmar todas as milícias populares, e defenderia o uso do campesinato para combater a "ameaça comunista" (Soto, 1994). Apesar do apoio da zona rural, o novo presidente apostaria no desenvolvimento agrário em larga escala no até então isolado departamento de Santa Cruz, no oriente boliviano, onde a tradição de organização sindical era mais insipiente. A disponibilidade de crédito nos mercados internacionais permitiu ao governo endividar-se para promover o desenvolvimento da região e a alta internacional nos preços da commodities levaria ao surgimento de uma nova elite latifundiária, composta inclusive por antigos proprietários afetados pela reforma agrária (Webber, 2011). Na presidência de Bánzer, os canais de negociação direta entre movimentos populares e o governo foram sendo progressivamente fechados, representando o desmoronamento definitivo do modelo surgido em 1952, onde a princípio a COB exerceria influência direta no gabinete presidencial do MNR, e em seguida o campesinato se firmara como instância basilar de suporte ao regime militar (Rivera, 2010; Webber, 2011). Logo após o golpe, a federação de camponeses emitiria uma nova nota agradecendo às

\footnotetext{
${ }^{4} \mathrm{~A}$ resistência de Torres em ceder postos-chave do seu governo às representações sindicais, como a pasta da Economia ou a presidência da COMIBOL, levou os trabalhadores a experimentarem com formas cada vez mais autônomas de organização política. Em maio de 1971, era anunciada a Asamblea Popular, um encontro nacional entre distintos movimentos populares, incluindo não apenas sindicatos, mas também estudantes e partidos, com fins a gerar um salto qualitativo em suas capacidades de deliberação, articulação e mobilização, a partir das teses políticas publicadas pela COB em 1970 (COB, 1970). Todavia, os mineiros acabariam desproporcionalmente representados no encontro, em detrimento do campesinato, minoria entre os presentes mesmo sendo a maior parcela da população. No final, Torres manteve-se firme em não permitir que os trabalhadores ganhassem uma maior influência em seu governo, afirmando ser o único possuidor de um mandato popular legítimo, e taxando as resoluções do encontro de 'observações', com a promessa de ouvi-las da mesma forma que seria feito com qualquer outro 'grupo de cidadãos' (Alexander, 2005, pp. 137-138).
} 
forças armadas por salvar o país da 'voracidade do anarquismo vermelho e da demagogia destrutiva' (Alexander, 2005, p. 142), mas não demoraria para que a zona rural também sofresse com o autoritarismo do novo governo.

Apesar dos estáveis níveis de crescimento econômico no começo do governo Bánzer, a situação fiscal do Estado boliviano tornava-se cada vez mais insustentável, em função do aumento vertiginoso da dívida pública causado pela abertura ao capital estrangeiro, estimulada pelos militares desde o governo Barrientos. A crise financeira internacional do começo da década de 1970 levaria ao anúncio de sequentes desvalorizações do peso boliviano, um duro golpe também para o campesinato. Uma nova geração de dirigentes locais, já distante das disputas que levaram ao rompimento entre as forças armadas e o MNR, mostrava-se cada vez mais descontente com os rumos do PMC. Em janeiro de 1974, um novo pacote econômico foi apresentado e sindicatos rurais promoveram o bloqueio da estrada que ligava Cochabamba a Santa Cruz. Quando os vinte mil manifestantes viram assomar ao longe os tanques do exército, foi exigido que o presidente viesse negociar diretamente com as lideranças, como havia sido feito desde a assinatura do PMC. Contudo, Bánzer ordenou que os soldados abrissem fogo e mais de oitenta pessoas foram assassinados. $\mathrm{O}$ episódio, para sempre marcado na história de martírio popular na Bolívia como o Massacre do Vale, representava o fim simbólico da aliança das forças armadas com o sindicalismo rural e, com ela, da ideia de que os militares visavam apenas garantir as conquistas populares de 1952 (Webber, 2011).

\section{O PASSADO E O PROGRESSO}

Antes de discutir as consequências do Massacre do Vale, e o gradual esgotamento do período militar na Bolívia, é preciso analisar as condições em que se deu o alinhamento entre as forças armadas e os setores populares do campo. O PMC fazia do campesinato, maioria absoluta da população, um ator reconhecível no interior da correlação de forças da política boliviana. Seu apoio era fundamental para a manutenção do governo. O alinhamento com esse setor representa uma transformação qualitativa no papel das forças armadas no interior do estado se comparado ao período anterior a 1952, quando representavam o principal ponto de apoio do governo oligárquico (Rivera, 2010). Barrientos seria positivamente lembrado, em um espaço rural carente da presença do poder público, pela provisão de serviços, com as forças armadas atuando na educação, na saúde, no abastecimento das famílias, em obras de infraestrutura e na mediação entre lideranças locais, em consonância com a estratégia dos EUA para que o fortaleci- 
mento do papel dos militares resultasse no desarmamento das tensões sociais (Soto, 1994). Com a transformação das relações entre estado e sociedade civil, iniciada em 1952, não havia mais espaço na Bolívia para um governo alheio à presença popular. Todavia, se o PMC permitira às forças armadas legitimidade enquanto continuadoras das reformas, ele representaria apenas uma das formas possíveis pelas quais o campesinato entraria na política nacional após a Revolução.

A vinculação do processo de parcelamento dos latifúndios à estrutura dos sindicatos resultaria em uma negociação sem intermediários com o poder público, possibilitando também o acesso a bens e serviços oriundos das cidades. Estes eram crescentemente escassos em um espaço rural cada vez mais mercantilizado, com a desagregação das grandes haciendas em pequenas propriedades individuais resultando em um modelo de usufruto da terra distinto daquele que caracterizava os ayllus indígenas, com seu cultivo comunitário, acarretando em uma crescente proletarização do campo. Ao mesmo tempo, a despeito de configurar-se enquanto o grupo social mais numeroso, o campesinato dependia da interlocução com algum setor específico do governo, seja o MNR, sejam as forças armadas, para fazer-se ouvido no debate público (Webber, 2011). Contudo, tanto a forma sindical de organização quanto a ideia de uma reforma agrária não foram propostas nascidas na cidade e levadas para o campo, mas processos gestados de maneira simultânea e dialógica, instrumentalizados por ambos os lados a partir das possibilidades de interlocução nascidas com a queda da rosca em 1952 (Rivera, 2010). ${ }^{5}$ A existência das populações rurais na política boliviana, antes, durante e após o PMC, passaria pela escolha de uma posição política mais ou menos autônoma no interior das disputas sociais correntes, diante do reconhecimento condescendente por parte dos grupos historicamente mais próximos ao poder. ${ }^{6}$

Os ayllus, especialmente no altiplano, haviam sido continuamente atacados pela especulação fundiária desde o final do século XIX, ainda mais, após a perda do território litorâneo para os chilenos, na Guerra do Pacífico (18791883). Em 1877, sua existência jurídica chegou a ser suspensa por lei, devido

\footnotetext{
${ }^{5}$ A demanda pelo fim das grandes propriedades começou a ganhar força no campo ainda no final da década de 1940, e foi com o lema de 'reforma, não revolução rural' que o MNR buscou, após chegar ao governo, hegemonizar essa rearticulação do acesso à terra, em meio à franca disputa entre o campesinato e a elite latifundiária decadente (Kohl, 1978).

${ }^{6}$ Anteriormente à reforma agrária, lideranças indígenas conhecidas por 'caciques apoderados' articulavam, junto a advogados urbanos, o resgate de antigos títulos de propriedade das terras dos ayllus, expedidos ainda no período colonial. A despeito de reconhecerem sua 'ignorância' diante das leis que emanavam desde as cidades (Marka Tola \& Caciques-Apoderados, 2018), os caciques eram ainda assim capazes de fazê-las trabalhar contrariamente aos interesses daqueles acostumados a operá-las.
} 
à ausência de títulos individuais de propriedade, em nome de uma isonomia de direitos entre todos os cidadãos. ${ }^{7}$ A escolha do sindicato cochabambino, oriundo de uma região com baixa presença indígena e historicamente formado pela união de pequenos proprietários, como arquétipo da reforma agrária é sintomática de como houve uma preferência por um campesinato mais adequado à visão movimientista: o espaço rural, organizado em pequenas e médias propriedades, seria responsável por abastecer as cidades e centros mineradores, mas sem tocar na ferida da desarticulação das comunidades indígenas, que levara à concentração fundiária no altiplano e à relegação dessas culturas ao passado (Rivera, 2010).

O sindicato camponês, portanto, representa uma instância ambivalente de reconhecimento das populações rurais e de suas demandas. Ele permitia a integração desses espaços locais a narrativas mais amplas de legitimidade política, sendo o caráter popular do governo nascido após 1952 fundamentado em reformas como a reorganização fundiária, a garantia do sufrágio irrestrito e a expansão da educação pública visando a alfabetização universal. Deixar para trás a condição de colono das antigas haciendas, e a herança indígena da vivência no interior dos ayllus, permitiria a esse nascente camponês moderno identificar-se como um cidadão boliviano pleno, no interior de um regime 'mestiço' de pertencimento que posicionava-se de maneira contrária à hierarquização racial explícita do período oligárquico. $\mathrm{O}$ governo revolucionário afirmava haver superado as antigas clivagens entre brancos e indígenas, classes médias e trabalhadores, com a eliminação da velha elite que usurpava as riquezas nacionais (Rivera, 2003). Como apontado no próprio decreto da reforma agrária, o 'problema indígena' não passava de uma questão de exploração econômica, e o apego aos modos de vida tradicionais haveria de desaparecer a medida que a modernidade se tornasse acessível a todos os bolivianos (Governo da Bolívia, 2018a).

As medidas anunciadas a partir de 1952, marcantes dessa entrada irreversível da questão popular na ordem política, são representativas dessa ambivalência. Se por um lado, a reforma agrária ampliava o acesso à terra e buscava substituir relações servis pelo trabalho assalariado, por outro, o fazia em detrimento dos territórios indígenas, importantes não por seu valor produtivo, mas por estarem intrinsecamente relacionados à estruturação político-cultural das próprias comunidades. Se a expansão da educação rural visava alfabetizar todos os bolivianos, incluindo-os na vida púbica, o enfoque no espanhol e na comunicação escrita

\footnotetext{
${ }^{7} \mathrm{O}$ decreto que regulamentava a propriedade rural individual afirmava explicitamente que nenhuma liderança indígena poderia falar em nome das comunidades como um todo. Caso houvesse resistência dos ayllus, os examinadores das terras tinham a permissão de declarar sua venda, com cada comunários recebendo sua 'devida' parcela individual do lucro (Governo da Bolívia, 2018b).
} 
ignorava as línguas indígenas e sua tradição oral, oficializando o idioma dos colonizadores como o do espaço comum. Por fim, se o sufrágio universal garantiu à população do campo a maioria proporcional do eleitorado, em contrapartida, sua participação política era restringida a um voto individual a cada quatro anos, em contraste com os modelos de lideranças rotativas e de tomada de decisão consensual que predominavam no cotidiano dos ayllus. Em suma, no interior do regime de 'cidadania mestiça', nascido após 1952, tornar-se boliviano significava tornar-se o arquétipo do habitante das cidades ou dos pequenos povoados rurais: dono de propriedade privada, letrado em espanhol e participe em um modelo democrático representativo. Ele é, em suma, o anti-indígena, uma negação explícita de qualquer contemporaneidade entre a Bolívia 'ocidentalizada' e essas culturas locais (Rivera, 2003).

A dificuldade de precisar as fronteiras entre indígenas e camponeses é assim resultado de um regime metonímico de reconhecimento. A identidade de uma parcela da população, as elites urbanas, é universalizada enquanto critério de pertencimento para a nova Bolívia moderna, que se afirma sobre os escombros do antigo estado oligárquico, derrubado em 1952. Uma vez expurgado esse inimigo interno, simbolizado pelos poderosos empresários da indústria mineradora e os donos das grandes propriedades rurais, seria possível que o país se desenvolvesse a partir das suas próprias características, sem a manutenção do domínio de uma classe, ou de uma raça, pela outra, mas através da inclusão de todos os cidadãos em um processo coletivo de consolidação nacional. ${ }^{8}$ Contudo, tanto esse nascente espaço comum quanto o processo histórico que leva a ele são guiados por seus próprios termos excludentes: não haveria lugar no presente para a indigeneidade, se o campo buscasse afirmar-se enquanto um interlocutor possível do poder público. A noção de uma 'cidadania mestiça' procurou afastar esses marcadores do pertencimento nacional de apenas um grupo específico da sociedade, as elites herdeiras da colonização espanhola, apontando para uma heterogeneidade constitutiva da Bolívia enquanto nação. Entretanto, ela acaba por também restringir o indígena ao passado, como um resquício folclórico que a marcha da história faria lentamente cair no esquecimento (Rivera, 2010). ${ }^{9}$

\footnotetext{
${ }^{8}$ Um dos principais ideólogos do movimientismo em seus anos iniciais, Carlos Montenegro foi um ferrenho crítico da 'antinação', da alienação dos interesses intrínsecos à Bolívia por um olhar fixado no exterior. Seu alvo favorito era o historiador Alcides Arguedas, cujo trabalho enfatizava a mestiçagem como um entrave para que o país se igualasse às demais nações modernas (Barragán, 2010). ${ }^{9} \mathrm{O}$ que ocorre aqui, ao invés de uma quebra com a ideologia racial das elites derrubadas com a Revolução, é mais como uma rearticulação dos termos em que a diferença é tratada. Se para os movimientistas a indigeneidade se tornava resquício de cultura local, a ser solapada pelo advento da Bolívia moderna, antes o recurso ao progresso temporal era feito de um modo mais literal. De
} 
Todavia, ao contrário da concepção de história avançada pelo MNR, em que as disputas coloniais haveriam de desaparecer com o advento da modernidade, esse presente, onde os sujeitos veem-se capazes de avançar um projeto de futuro fundado em mudanças no status quo, é marcado pelo resgate dos sentidos passados, em uma contemporaneidade continuamente em produção (Rivera, 2012). Essa substituição da identidade indígena pela camponesa diz buscar a superação da cisão da Bolívia em duas: uma oriunda da ocupação espanhola, outra associada à manutenção dos estilos de vida anteriores à colonização. Entretanto, esse enquadramento da problemática procura pela reunificação de um corpo coletivo que nunca existiu. Este acaba sendo continuamente significado e produzido a partir dos marcadores de uma parcela constituída exatamente através dessa divisão que se busca superar: o cidadão moderno, o não-indígena (Reinaga apud. Silva, 2018, pp. 270-1). Não há lugar nessa Bolívia para a diferença colonial, mas, ao mesmo tempo, ela é condição necessária e anterior para que o país possa ser produzido e possa assumir esse particular regime histórico de existência. Sem essa constatação acerca da justaposição do moderno sobre o tradicional, não é possível entender o alinhamento e o posterior rompimento do campesinato com os militares, pois é esse reconhecimento que permite a essas populações algum tipo de existência no interior do espaço comum boliviano e, ao mesmo tempo, gera alternativas para subvertê-lo.

\section{O RETORNO DE KATARI}

O Massacre do Vale de 1974 se daria em meio à escalada autoritária de Bánzer. Até o final desse ano, toda a base civil desembarcaria da coalisão de governo, deixando uma administração composta somente por militares. Até então, o presidente contava com o apoio de setores mais à direita do espectro político, inclusive de algumas vertentes do MNR. Com a preocupação de que os movimientistas fossem capazes de recuperar sua antiga base de apoio, o presidente emitira, ao final de 1973, decretos que garantiam ao governo a prerrogativa de apontar os cargos de liderança no interior das entidades sindicais. Os trabalhadores

acordo com o censo boliviano de 1900 (Governo da Bolívia, 2018c), a raça indígena estaria condenada ao desaparecimento, em função dos processos naturais de choque e evolução das civilizações. $\mathrm{O}$ documento serviria de prenuncio a uma era de estudos antropológicos, preocupados com a "degradação" das culturas indígenas. Pesquisas arqueológicas a respeito de sociedades como Tiahuanaco, baseadas na hipótese histórica de um conflito contínuo entre raças (a queda do império para os Incas e posteriormente a conquista destes pelos espanhóis), seriam relidas após 1952, como a narrativa de uma origem mitológica para os povos indígenas bolivianos, mas mesmo assim condizente com seu lugar em um passado já superado (Quisbert, 2004). 
mineiros continuariam representando o principal front de resistência ao regime e suas investidas corporativistas, afirmando seu apoio às teses políticas aprovadas na convenção da COB de 1970, de forte viés anti-imperialista e socialista (Alexander, 2005). ${ }^{10}$

Na segunda metade da década, viria crescer com a virada na política externa dos EUA em relação às ditaduras latino-americanas sob a administração Jimmy Carter as denúncias de violações de direitos humanos por parte do governo Bánzer. Este último se via cada vez mais isolado internacionalmente e das bases populares, dispondo de maneira crescente da violência para manter-se no poder (ibid.). Nesse período, o protagonismo popular exercido, desde a década de 1940, pelos trabalhadores mineiros seria ofuscado pelo surgimento de uma nova tendência no interior do sindicalismo rural: o movimento indígena. Diferentemente das mobilizações ocorridas antes da reforma agrária, a emergência de pautas ligadas à questão cultural no interior das entidades camponesas visava influir diretamente no debate nacional e não apenas defender os interesses da parcela da população identificada com o modo de vida dos ayllus. Essa virada teria por protagonista o movimento katarista, batizado em homenagem ao comandante da revolta indígena de 1781, Tupac Katari. O quase sucesso de Katari em tomar La Paz, sitiada por mais de cem dias, ficaria permanentemente marcado na memória boliviana, em ambos os lados da divisa colonial. Por um lado, o medo da 'massa indígena' serviria de pano de fundo para todo o projeto de integração das populações rurais após a independência, contrastando a declarada superioridade natural da cultura europeia à percepção de que estas constituíam um contingente populacional inquestionavelmente mais numeroso. Sem o controle e disciplinamento contínuo, o projeto civilizacional se encontraria em risco. Do outro lado, a frase atribuída a Katari, de que sua morte não colocaria fim à rebelião, pois ele haveria de retornar convertido em 'milhares de milhares', ressoaria durante décadas entre a militância indígena como a promessa de que não importa quão pesada fosse a violência imposta, ela jamais esgotaria sua capacidade de rearticular-se e manter-se acesa, em todo esse imenso contingente, como chama da revolta (Rivera, 2010).

A configuração particular que o katarismo tomou no interior da correlação de forças populares na Bolívia é indicativa de que essa rebeldia não derivava

\footnotetext{
${ }^{10}$ Escritas na esteira dos eventos de maio de 1968, e em meio à descolonização africana, as teses (COB, 1970) afirmavam o compromisso com um socialismo internacionalista, fundado na solidariedade entre distintos movimentos populares na Bolívia e ao redor do mundo. Elas criticavam diretamente as tentativas do governo Ovando de recriar o espírito 'reformista' da 1952, afirmando que era necessário apostar em caminhos que não a conciliação, e que fossem além de pautas econômicas.
} 
somente de uma memória que se recusa a ser apagada, mas, também de uma experiência oriunda das contradições do próprio presente histórico. As bases do movimento surgiriam da mobilização de estudantes aimarás nas periferias de La Paz, descendentes de famílias camponesas que haviam migrado para as cidades após as pequenas propriedades resultantes da reforma agrária não comportarem o crescimento da população rural. O massivo deslocamento de pessoas para os centros urbanos, ao longo das décadas de 1960 e 1970, levaria ao surgimento de bairros inteiros compostos por indígenas, onde os jovens, diante da experiência cotidiana de discriminação, se inspiravam nas histórias contadas por seus antepassados de resistência dos ayllus (Hashizume, 2015). Esses militantes encontrariam no trabalho de Fausto Reinaga uma importante referência intelectual para fazer sentido da discriminação a que eram submetidos (Escárzaga, 2012). Voraz leitor de Frantz Fanon, Reinaga buscaria adaptar à questão da indigeneidade o debate da negritude, em voga na década de 1960, a partir de uma crítica a como se dera na Bolívia a inclusão das populações racializadas. Ele se nomearia fundador do Indianismo que, em contrastes com os autores brancos do Indigenismo do começo do século XX, estaria preocupado não somente com o estudo estético das culturas pré-coloniais, ou até mesmo com a denúncia espúria e condescendente da situação social dessas populações, mas em delimitar as bases críticas para um processo emancipatório (Lucero, 2008).

Sua obra mais famosa, La Revolución Índia, começa de onde Os Condenados da Terra termina, afirmando que apegar-se à civilização ocidental seria o mesmo que deixar-se conduzir por um modelo de sociedade já em crise. $\mathrm{O}$ autor demonstra especial interesse pela última frase da obra de Fanon que, em sua tradução para o espanhol, vai caracterizar a transformação necessária para o desenvolvimento dessa consciência contestatória como uma 'troca de pele' (ibid.). Para o indianista, deixar para trás as amarras coloniais passaria por uma recusa em aceitar esse processo de aculturação:

A palavra 'camponês' é um disfarce branco. Ao nos chamarem 'camponeses' nos disfarçam, assim como nos puseram sapatos, colarinho e gravata, assim querem pôr em nós, ou nos fazer crer que sim, uma outra cara, um outro couro, uma outra alma; [...] O indígena foi indígena, é indígena e tem que liberar-se indígena [...] As massas que trabalham nos sumidouros das minas, nas fábricas, são indígenas de carne e alma [...] o habitante das comunidades ou o antigo servo no latifúndio [...] não é um 'camponês' [...]O indígena não é uma classe social [...]. O camponês autêntico luta pelo salário. [...] $\mathrm{O}$ indígena não luta pelo salário, que nunca conheceu; ou pela justiça social, que sequer imagina. $\mathrm{O}$ indígena luta pela justiça racial, pela liberdade de sua raça [...] O problema do indígena não é questão de integração ou assimilação à sociedade branca civilizada, o problema do indígena é de liberação (Reinga apud. Escárzaga, 2012, p. 192) 
A temática que liga o indianista à Fanon é a forma como essa condição racializada do sujeito haveria de ser continuamente redescoberta, através da experiência vivida de discriminação. A despeito de diferir do pensador martinicano ao colocar uma maior ênfase no caráter atemporal da identidade indígena (Silva, 2018), Reinaga faria coro à sua leitura dessa disputa colonial não como algo pertencente ao passado, um resquício a ser eliminado com o desenrolar do processo histórico, mas através da configuração particular que ela assume no interior desse presente moderno. É por meio da revolta diante da discriminação que o sujeito torna-se capaz de enxergar para além da fachada de tolerância levantada diante dele, e divisar as bases de um processo de mudança alternativo às possibilidades então apresentadas (Escárzaga, 2012).

Esse enquadramento da questão indígena, que problematiza uma leitura linear e unidirecional do desenvolvimento econômico e social, ficaria explícito no retorno ao campo dos jovens katarista, em busca de estabelecer canais de comunicação com as populações rurais (Rivera, 2010). Em documentos como o Manifesto de Tiahuanaco, de 1973 (MINK'A, et al., 1986), eles colocariam a pauta indígena como um fundo comum a todas as lutas populares na Bolívia e conclamariam as populações rurais a rejeitarem o papel subordinado que as demais forças políticas, até aquelas que se declaravam como aliadas, lhes insistiam em atribuir. ${ }^{11}$ Os kataristas fundariam centros culturais, cujos programas de rádio em quéchua e aimará iriam levar esses ideais de radicalização política aos recantos mais remotos e iletrados da zona rural. Sua ligação com a cultura popular permitiria que escapassem da censura do governo Bánzer e o movimento ganhava cada vez mais apoio entre setores do sindicalismo rural descontentes com o PMC. Ao final da década de 1970, os kataristas já se apresentavam como a principal tendência no interior do movimento camponês e o acréscimo de suas forças às mobilizações lideradas pela $\mathrm{COB}$ tornaria a pressão popular forte demais para o governo Bánzer suportar (Rivera, 2010).

\footnotetext{
${ }^{11}$ A princípio, um documento em favor de mudanças na educação rural, o Manifesto (MINK'A et al., 1986) questiona a transposição para o campo de modelos educacionais alheios aos valores e à realidade das comunidades indígenas, no contexto de um questionamento mais amplo à continuidade das práticas culturais e econômicas de opressão colonial posteriormente ao surgimento da república boliviana. A escola rural fora por muitas décadas, assim como o sindicato camponês, um espaço de disputa entre instituições associadas à vida urbana e ocidentalizada, por um lado, e a busca das comunidades indígenas por mediar os termos de sua integração, por outro (Rivera, 2010). A crítica historiográfica à leitura de independência como um rompimento com a colonialidade ganhou força no começo da década de 1970, com intelectuais aimarás como Roberto Choque Canqui galgando degraus nas universidades de La Paz (Barragán, 2010).
} 
A apertura anunciada em 1978 pelo regime viria consolidar a aproximação entre os diversos movimentos de trabalhadores, oriundos tanto do campo quanto das minas e centros urbanos. O período durante 1980, em que Jenaro Flores, principal líder katarista, ocupou o mais importante cargo no interior da COB é demonstrativo de como a reaproximação entre os distintos movimentos de trabalhadores confrontava os termos hierarquizados vigentes até então (ibid.). Entre 1978 e 1982, a Bolívia passaria por oito presidentes distintos, com uma série de golpes de estado demonstrando a reticência das forças armadas em permitir que a oposição, por tanto tempo perseguida, assumisse para si a capacidade de fazer justiça pela violência perpetrada ao longo do período autoritário. A cada tentativa de frustrar a abertura democrática, a união entre os diversos movimentos sindicais apresentaria uma capacidade de mobilização popular que não era vista desde a Revolução Nacional, realizando greves gerais, protestos massivos nas cidades e o bloqueio das principais estradas do país. Com a eleição de Hernán Siles Suazo, em 1982, chegava ao fim a longa noite dos generais, e iniciava-se um novo capítulo da história boliviana, marcado pelas reformas neoliberais que poriam mais uma vez em movimento as forças populares (Alexander, 2005). Todavia, estas não eram mais as mesmas de 1952, pois as experiências de luta e resistência frente ao regime militar haviam desdobrado de maneiras complexas e inovadoras os sentidos de sua presença e sua capacidade política na história da Bolívia.

\section{CONCLUSÃO}

É uma difícil tarefa debruçar-se sobre o apoio dos sindicatos rurais ao regime militar na Bolívia. Em cada definição de progresso social reside a manutenção de uma determinada ordem para esse coletivo, o resguardo de uma hierarquia entre a presença de certas identidades aceitáveis e a negação de outras que já não possuem mais lugar nesse espaço compartilhado. Em cada apelo à universalidade, que busca abranger todos os bolivianos, reside o repúdio a um particular, cuja manifestação põe em risco a própria viabilidade dessa concepção do coletivo. Para o campesinato oficialista, se o objetivo é o reconhecimento das necessidades do espaço rural perante o estado, não havia como suportar o radicalismo daqueles que desejam colocar sua própria ação, sua própria visão revolucionária do conflito social, como representativa de todos os setores populares. Já para os sindicatos mineradores e urbanos, se o fim é a revolução, é preciso deixar de lado o apego dos camponeses à terra, em prol dos objetivos comuns aos trabalhadores. A forma como os limites do espaço coletivo são demarcados, negociados, subvertidos e questionados, dita os ritmos tanto dos processos de inclusão, quanto daqueles 
de marginalização. Ao mesmo tempo, é através dessa complexa articulação e sobreposição de sentidos que irão emergir tendências distintas, críticas a essa concordância entre a integração das populações advindas do campo, por um lado, e a preocupação com a estabilidade nacional como expressa pelos militares, por outro.

Olhar para o período militar da Bolívia como um subproduto das disputas ideológicas travadas a nível internacional nos faria ignorar essas fronteiras, partindo de categorias abstratas como 'camponeses' e 'indígenas' com fins de descrever uma realidade onde esses significantes são incessantemente reinterpretados e subvertidos. Por outro lado, questionar esses marcadores do progresso, a hierarquização entre o passado e o futuro, nos permite enxergar o presente histórico como um espaço coletivo em constante elaboração e disputa. Ao invés de uma contraposição estrita entre o PMC e o katarismo, analisar criticamente as condições de possibilidade para que as posições sociais sejam lidas de maneira objetiva nos leva a indagar sobre os riscos de olhar para essas identidades sem ter em conta seu caráter intrinsecamente relacional. Assim, buscou-se aqui contrastar distintas fontes históricas e historiográficas, análises estruturais e diagnósticos conjunturais, com fins a refletir sobre o papel produtivo do discurso e da narrativa em um espaço coletivo sob disputa. Abordar as ambivalências do processo de integração e as subversões presentes em projetos contestatórios nos põe diante da contínua tarefa de fazermos sentido do passado em suas leituras contraditórias, como coloca White (1980), a partir das necessidades que somente conseguimos perceber desde o presente.

A concepção temporal dos aimará dá grande ênfase à maneira como somos cegos ao futuro, e a como enxergamos e nos guiamos primordialmente por aquilo que já está em nosso passado (García-Pabón, 2001). Ao deslocarmos a junção de distintas referências históricas em uma leitura coesa dos conflitos sociais, não recaímos em um relativismo onde toda interpretação se torna possível, mas nos obrigamos a ver como essas categorias emanam de uma relação contingente com a alteridade, sujeita a rearticulações inovadoras e transgressoras (Shapiro, 2013). Trazer esse olhar para o período militar latino-americano nos permite uma outra sensibilidade a respeito de como projetos coletivos são tecidos e como circulam entre os sujeitos políticos, assumindo tração e moldando suas posições visà-vis as fronteiras desse espaço comum. Ao invés de hierarquias fáceis entre as distintas orientações que acabam por ver no indígena o pequeno-burguês preocupado apenas com a propriedade de sua terra, podemos então tratar essas idiossincrasias como o espaço desde onde projetos de emancipação são capazes de emergir, em arranjos genuinamente inovadores e contestatórios. 


\section{REFERÊNCIAS BIBLIOGRÁFICAS}

Alexander, R. (2005). A History of organized labour in Bolivia. Praeger.

Barragán, R. (2010). Legitimidad de la historia o historia de la legitimidad: Releyendo 200 años después la 'Revolución del 16 de Julio de 1809' en Bolívia. Nordic Journal of Latin American and Caribbean Studies 40(1-2), 73-89. https://doi.org/10.16993/ibero.54

Central Obrera Boliviana (COB). (1970). Tesis politicas de la Central Obrera Boliviana. http://www.fundesnap.org/files/3_te- sis_politica_de_la_cob.pdf

Escárzaga, F. (2012). Comunidad indígena y revolución en Bolivia: El pensamento indianista-katarista de Fausto Reinaga y Felipe Quispe. Política y Cultura, (37), 185-210.

García-Pabón, L. (2001). The Clandestine nation: Indigenism and national subjects of Bolivia in the films of Jorge Sanjínes. Jump Cut, (44). http://www.ejumpcut.org/archive/jc44.2001/garcia/garciaforsite.html

Governo da Bolívia. (2018a). "Land to those who work it”. In S. Thomson, R. Barragán, X. Albó, S. Qayum \& M. Goodale (eds.), The Bolivia reader: History, culture, politics (pp. 278286). Duke University Press.

Governo da Bolívia. (2018b). Disentailment and its discontents. In S. Thomson, R. Barragán, X. Albó, S. Qayum \& M. Goodale (eds.), The Bolivia reader: History, culture, politics (pp. 184-187). Duke University Press.

Governo da Bolívia. (2018c). The slow and gradual disappearance of the indigenous race. In S. Thomson, R. Barragán, X. Albó, S. Qayum \& M. Goodale (eds.), The Bolivia reader: History, culture, politics (pp. 251-256). Duke University Press.

Hashizume, M. (2015). Colonialidades em xeque: Lições a partir da experiência do movimento katarista da Bolívia. The Postocolonialist, 2(2). https://estudogeral.sib.uc.pt/bitstream/10316/32965/1/Colonialidades\%20em\%20xeque $\% 20 \%$ e2\%80\%93\%20Li\%c3\%a7\%c3\%b5es\%20a\%20partir\%20da\%20experi\%c3\%aancia\%20do\%20movimento $\% 20 \mathrm{katarista} \% 20 \mathrm{da} \% 20 \mathrm{Bol} \% \mathrm{c} 3 \%$ advia.pdf

Kohl, J (1978). Peasants and Revolution in Bolivia, April 9, 1952 - August 2, 1953. The Hispanic American Historical Review, 58(2), 238-259. https://doi.org/10.1215/0018216858.2.238

Lora, G. (1977). A history of the Bolivian labour movement. Cambridge University Press. https://doi.org/10.1017/CBO9780511759598

Lucero, J. (2008). Fanon in the Andes: Fausto Reinaga, Indianismo, and the Black Atlantic. International Journal of Critical Indigenous Studies, (1), 13-22. https://doi.org/10.5204/ijcis.v1i1.19

Marka Tola, S., \& Caciques-Apoderados. (2018). The laws of the land. In S. Thomson, R. Barragán, X. Albó, S. Qayum \& M. Goodale (eds.), The Bolivia reader: History, culture, politics (pp. 327-330). Duke University Press.

Mink'a, et al. (1986). Primer Manifesto de Tiahuanaco. In J. Hurtado (ed.), El Katarismo. HISBOL.

Pearse, A. (1972). Peasant and revolution: The case of Bolivia. Economy and Society, 1(4), 399424. https://doi.org/10.1080/03085147200000022

Quisbert, P. (2004). "La glória de la raza": Historia prehispánica, imaginários y identidades entre 1930 y 1950. Estudios Bolivianos, (12), 177-212. 
Rivera C. S. (2003). El mito de la pertenencia de Bolívia al mundo "occidental": Réquiem para um nacionalismo. Temas Sociales, (24), 64-100.

Rivera C. S. (2010). Oprimidos pero no Vencidos: Luchas del campesinato aymara y qhwechwa 1900-1980. La Mirada Salvaje.

Rivera C. S. (2012). Ch'ixnakax utxiwa: A reflection on the practices and discourses of decolonization. The South Atlantic Quarterly, (111), 95-109. https://doi.org/10.1215/003828761472612

Shapiro, M. (2013). Studies in trans-disciplinary methods: After the aesthetic turn. Routledge. https://doi.org/10.4324/9780203101506

Silva, A. (2018). O Pensamento de Fausto Reinaga à luz de Franz Fanon. Revista Sul-Americana de Ciência Política, (4, 2), 269-287.

Soto, C. (1994). Historia del Pacto Militar-Campesino. CERES.

Webber, J. (2011). Red-October: Left-indigenous struggles in modern Bolivia. Brill. https://doi.org/10.1163/ej.9789004201552.i-376

White, H. (1980). The value of narrativity in the representation of reality. Critical Inquiry, 7(1), 5-27. https://doi.org/10.1086/448086 